\title{
JENIS-JENIS HYMENOPTERA PARASITOID DAN PERSENTASE PARASITASI TERHADAP BERBAGAI ULAT PEMAKAN DAUN KELAPA SAWIT DI KEBUN CIKASUNGKA PTPN VIII, CINDALI, BOGOR
}

\author{
Ichsan Luqmana Indra Putra \\ Fakultas Sains dan Teknologi Terapan, Program Studi Biologi, Universitas Ahmad Dahlan \\ e-mail : ichsan.luqmana@bio.uad.ac.id
}

\begin{abstract}
Abstrak
Minyak kelapa sawit adalah salah satu komoditas perkebunan di Indonesia dan telah tersebar luas di Indonesia. Salah satu hama yang menyerang kelapa sawit adalah serangga, dan hama yang paling merusak biasanya dari Lepidoptera. Tujuan dari penelitian ini adalah untuk menentukan parasitoid yang memparasitisasi hama pemakan daun kelapa sawit di perkebunan kelapa sawit PTPN VIII Cindali, Bogor. Penelitian dilakukan di 6 blok perkebunan kelapa sawit PTPN VIII Cindali dari September 2014 - Juni 2015 dengan pengamatan sebulan sekali. Sampel diambil dengan cara masingmasing blok diambil 5 tanaman di setiap plot secara acak untuk diamati dan serangga pemakan daun palem diambil untuk disimpan sampai parasitoid muncul. Parasitoid yang keluar kemudian dihitung dan diidentifikasi. Hasil penelitian menemukan 6 spesies hama pemakan daun palem dan 5 spesies Hymenoptera parasitoid yang memparasit hama ini. Hama yang ditemukan adalah Setora nitens, Amatissa sp., Birthosea bisura, Mahasena corbetti, Metisa plana dan Pseudococcus sp. Sedangkan parasitoid yang ditemukan adalah Spinaria spinator, Charops bicolor, Telenomus podisi, Aphanogmus sp. dan Acerophagus sp.

Kata kunci: Hymenoptera, minyak sawit, parasitisasi, parasitoid, Spinaria spinator, Setora nitens
\end{abstract}

\begin{abstract}
Palm oil is one of the plantation commodities in Indonesia and had widespread in Indonesia. One of pests that attack oil palm is insect, and the most damaging pests usually from Lepidoptera. The aim of this study was to determine the parasitoids that parasitize palm leaf-eating pests in the oil palm plantation of PTPN VIII Cindali, Bogor. The study was conducted in 6 blocks of PTPN VIII Cindali oil palm plantation from September 2014 - June 2015 with observations once a month. Sample was taken by means of each block taken 5 plants in every plots randomly to be observed and palm leaf-eating insects taken to kept until the parasitoid was emerged. The outgoing parasitoids then counted and identificated. The results of the study founds 6 species of palm leaf-eating pests and 5 species of Hymenoptera parasitoids that parasitize these pests. Pests that found were Setora nitens, Amatissa sp., Birthosea bisura, Mahasena corbetti, Metisa plana and Pseudococcus sp. Whereas parasitoids that found were Spinaria spinator, Charops bicolor, Telenomus podisi, Aphanogmus sp. and Acerophagus sp.

Kata kunci: Hymenoptera, palm oil, parasitization, parasitoids, Spinaria spinator, Setora nitens
\end{abstract}

\section{PENDAhUluan}

Kelapa sawit merupakan tanaman perkebunan yang menghasilkan devisa non migas bagi Indonesia. Salah satu perusahaan kelapa sawit yang merupakan Badan Usaha Milik Negara (BUMN) adalah PT Perkebunan Nusantara (PTPN) VIII. Dalam budidayanya, PTPN VIII memiliki hambatan dalam meningkatkan produksi kelapa sawit. Salah satu hambatan tersebut adalah serangga hama. Beberapa serangga yang telah diketahui menjadi hama pada tanaman kelapa sawit di berbagai daerah, khususnya sebagai pemakan daun, Setothosea asigna van Eecke (Lepidoptera: Limacodidae), Setora nitens Walker (Lepidoptera:
Limacodidae), Darna trima Moore (Lepidoptera: Limacodidae), Metisa plana Walker (Lepidoptera: Psychidae), Mahasena corbetti Tams (Lepidoptera: Psychidae), Cremastopsyche pendula de Joannis (Lepidoptera: Psychidae), Brachycyttarus griseus de Joannis (Lepidoptera: Psychidae), Manatha albipes Moore (Lepidoptera: Psychidae), Amatissa sp. (Lepidoptera: Psychidae), dan Cryptothelea cardiophaga Westw. (Lepidoptra: Psychidae) (Kiswanto et al. 2008).

Pengendalian ulat pemakan daun kelapa sawit yang sering dilakukan adalah dengan penyemprotan insektisida karena menunjukkan hasil yang instan. Akan tetapi, dampak dari pengguna- 
an insektisida tesebut dapat memengaruhi keadaan lingkungan sekitar. Dewasa ini penggunaan musuh alami sudah banyak dilakukan dalam hal pengendalian populasi hama perkebunan. Salah satunya adalah dengan pemanfaatan parasitoid.

Menurut penelitian dari Idris (2001), terdapat 17 subfamili Braconidae dan 13 subfamili Ichneumonidae yang terdapat di perkebunan kelapa sawit di Malaysia. Sedangkan menurut Hindarto (2015), terdapat 20 famili Hymenoptera parasitoid yang terdapat di kebun kelapa sawit di Medan. Hymenoptera parasitoid yang telah digunakan dalam perkebunan kelapa sawit diantaranya Braconidae (Hanysyam et al. 2013), Ceraphronidae (Kamarudin et al. 1996), Eulophidae (Hertslet \& Duckett 1971), Ichneumonidae (Mariau 1999), Encyrtidae (Blumberg 2008); Aphelinidae (Blumberg 2008) dan Trichogrammatidae (Rao et al. 1971). Sedangkan spesies parasitoid yang telah digunakan dalam pengendalian hama pemakan daun kelapa sawit adalah Spinaria spinator (Guérin-Méneville) (Hanysyam et al. 2013), Aphanogmus thylax Polaszek dan Dessart (Kamarudin et al. 1996), Fornicia sp. (Hymenoptera: Braconidae), Euplectromorpha spp. (Hymenoptera: Eulophidae) dan Chlorocryptus purpuratus (Smith) (Hymenoptera: Ichneumonidae) (Mariau 1999). Selain itu, persentase parasitisasi parasitoid terhadap ulat pemakan daun kelapa sawit juga ditemukan cukup tinggi di lapang. Sebagai contoh pada Metisa plana tingkat parasitisasi $\mathrm{Co}$ tesia metesae sampai 51\%; Brachymeria carinata 28\%; Busymania oxymora 13\%; Goryphus bunoh 8\%; Pediobius sp. 5\%; dan Eupelmus cotoxanthae 2\% (Halim et al. 2017). Penelitian lain mengatakan bahwa parasitisasi larva Dasychra mendosa oleh parasitoid Eniscopilus dasychirae di lapang mencapai $14 \%$ dan oleh Brachymeria megaspila sampai 38\% (Dhileepan 1996). Sedangkan menurut Cheong et al (2010), larva dari Pteroma pendula memiliki serangan tertinggi dari Pediobius imbrues Walker $(67,4 \%)$.

Mengingat pentingnya peranan Hymenoptera parasitoid, maka penelitian tentang Hymenoptera parasitoid yang memarasit ulat pemakan daun kelapa sawit di PTPN VIII Cindali perlu dilakukan sebagai kajian awal dalam pemanfaatannya sebagai agens pengendalian hayati. Penelitian bertujuan mengetahui Hymenoptera parasitoid yang memarasit hama ulat pemakan daun di kebun kelapa sawit PTPN VIII, Cindali Bogor.

\section{METODE PENELITIAN \\ Tempat dan Waktu}

Penelitian dilaksanakan di kebun kelapa sawit PTPN VIII Afdeling 1 Cindali, Bogor. Pelaksanaan penelitian dilakukan pada bulan September 2014 - Juni 2015. Identifikasi sampel dilakukan di Laboratorium Biosistematika Serangga, Departemen Proktesi Tanaman, Fakultas Pertanian, Institut Pertanian Bogor.

\section{Pengambilan Sampel Hama Pemakan Daun Kelapa Sawit}

Pengamatan dan pengambilan sampel dilakukan pada 2 pohon kelapa sawit pada tiap plot. Hama yang diamati adalah hama pemakan daun kelapa sawit yang terdapat pada pelepah bagian bawah daun kelapa sawit. Pada setiap pohon diamati 5 pelepah daun, total dalam satu blok terdapat 50 pelepah daun. Pada setiap plot dilakukan pemotongan satu pelepah daun kelapa sawit. Hama yang ditemukan (baik berupa telur, larva atau pupa) kemudian dipelihara di laboratorium dan diamati Hymenoptera parasitoid yang keluar. Pemeliharaan dilakukan di wadah berdiameter $6 \mathrm{~cm}$ dan tinggi sekitar $15 \mathrm{~cm}$. Pada dasar wadah diberi tisu yang dibasahi untuk menjaga kelembaban. Wadah ditutup dengan kain kasa yang diikat dengan karet gelang. Dalam 1 wadah berisi 1 larva. Apabila pakan berkurang, akan ditambahkan pakan berupa potongan daun kelapa sawit. Kotoran yang menumpuk pada wadah dibersihkan setiap hari untuk menjaga kebersihan wadah pemeliharaan. Parasitoid yang keluar dari inang yang terparasit diambil dan dimasukkan ke dalam microtube $1 \mathrm{~mL}$ berisi alkohol $70 \%$ untuk kemudian diidentifikasi sampai tingkat morfospesies.

\section{Analisis Data}

Hymenoptera parasitoid yang didapat kemudian diidentifikasi menggunakan buku acuan. Identifikasi dilakukan dengan cara membandingkan ciri morfologi dari specimen yang didapat dengan ciri morfologi yang berada pada buku acuan identifikasi. Buku acuan yang digunakan adalah Hymenoptera of The World (Goulet \& Huber 1993), Annotated Keys to the Genera of Neartic Chalcidoidea (Gibson et al. 1997), dan A 
Handbook of The Families of Nearctic Chalcidoidea (Hymenoptera) (Grissell \& Schauff 1990). Hasil identifikasi kemudian dianalisis untuk melihat hubungan parasitoid dengan hama pemakan daun kelapa sawit pada lokasi pengambilan sampel. Untuk menghitung persen parasitisasi $\mathrm{Hy}-$ menoptera parasitoid soliter digunakan rumus sebagai berikut :

$$
I P=\frac{N 2}{N 1} \times 100 \%
$$

Untuk menghitung persen parasitisasi Hymenoptera parasitoid yang bersifat gregarious digunakan rumus :

$$
I P=\frac{N 2+N 1}{N 1} \times 100 \%
$$

Keterangan:

IP : Indeks Parasitisasi

N1 : Jumlah sampel (telur, larva, dan atau pupa) yang diambil dari lapang dan dipelihara di laboratorium

N2 :Jumlah sampel (telur, larva, dan atau pupa) yang terserang parasitoid

\section{HASIL DAN PEMBAHASAN}

\section{Jenis dan Kelimpahan Hama Pemakan Daun Kelapa Sawit dan Hymenoptera Parasitoidnya}

Hasil menunjukkan bahwa di kebun kelapa sawit PTPN VIII Cindali, Bogor ditemukan 6 jenis hama pemakan daun kelapa sawit dan 5 Hymenoptera parasitoid yang memarasitnya (Tabel 1).

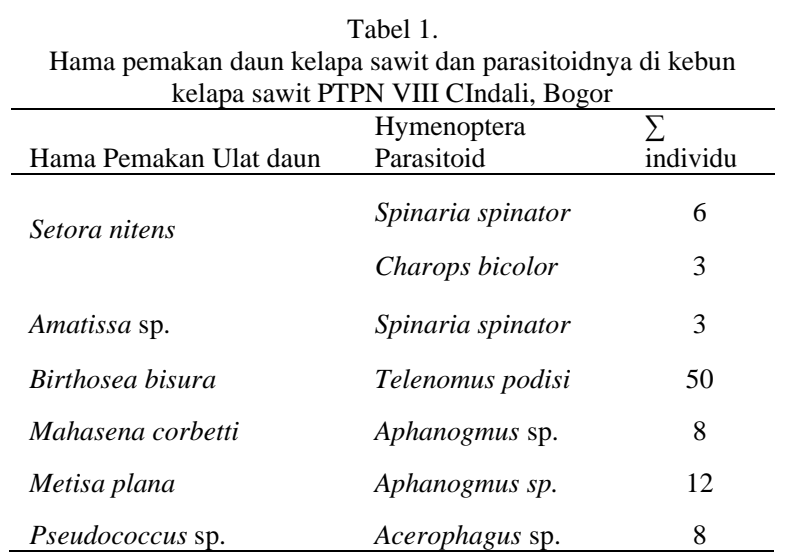

Dari ke-lima parasitoid yang ditemukan, 2 parasitoid merupakan parasitoid penting pada hama pemakan daun kelapa sawit. Ke-dua parasitoid tersebut adalah $S$. spinator dan Aphanogmus sp. $S$ spinator diketahui telah menjadi parasitoid uta- ma pada ulat api di kebun kelapa sawit (Hanysyam et al. 2013). Sedangkan Famili Ceraphronidae merupakan salah satu musuh utama pada ulat kantung di kebun kelapa sawit (Kamarudin et al. 1996). Aphanogmus sp. telah diketahui memarasiti ulat kantung M. plana dan M. corbetti (Kamarudin et al. 1996). Menurut Cock et al. (2008), Aphanogmus sp. menjadi parasitoid sekunder yang memarasit hama baru dari genus Penthocrates Meyrick (Lepidoptera: Limacodidae) di Filipina. Spesies dari genus Aphanogmus yang diketahui sebagai parasitoid pada hama pemakan daun kelapa sawit adalah Aphanogmus thylax Polaszek dan Dessart (Kamarudin et al. 1996).

Selain parasitoid yang terdapat dalam table tersebut, terdapat 1 parasitoid lain yang ditemukan yang merupakan parasitoid potensial untuk $B$. bisura (Mariau, 1999). Parasitoid tersebut adalah Chlorocryptus purpuratus (Smith). Parasitoid ini ditemukan memarasit ulat tersebut di perkebunan kelapa sawit di Malaysia (Mariau 1999). Parasitoid ini ditemukan di kebun kelapa sawit melalui penangkapan dengan menggunakan perangkap, tetapi tidak ditemukan saat pemeliharaan ulat $B$. bisura. Hal ini dapat disebabkan karena ketika parasitoid tersebut ada, namun inangnya belum tersedia, dan ketika inangnya tersedia parasitoidnya tidak ditemukan atau belum ditemukan memarasit larva dari ulat tersebut.

Banyaknya parasitoid yang ditemukan memarasit hama pemakan daun kelapa sawit pada lokasi sampling dikarenakan tersedianya inang yang melimpah bagi parasitoid tersebut. Semakin banyak inang bagi parasitoid, maka semakin banyak parasitoid yang terdapat pada area tersebut (Costamagna et al. 2004; Kaeslin et al. 2004). Inang dan parastoid sangat berhubungan erat, ketiadaan inang dapat memengaruhi keberadaan suatu parasitoid, akan tetapi parasitoid juga dapat mencari inang alternatif lain sehingga keberlangsungan hidup dari parasitoid tersebut juga tetap terjaga (Marino et al. 2005; Pratissoli et al. 2009). Selain itu tersedianya vegetasi lantai selama penelitian juga memengaruhi fluktuasi dari parasitoid tersebut. Semakin beragam vegetasi bawah maka semakin beragam dan melimpah juga ketersediaan inang dan tambahan nutrisi bagi parasitoid tersebut. Semakin banyak vegetasi bawah yang tersedia pada suatu ekosistem, maka akan lebih banyak juga tersedia inang alternative 
bagi parasitoid tersebut. Selain itu, vegetasi bawah yang berbunga juga dapat dijadaikan sebagai tambahan nutrisi bagi parasitoid untuk mempertahankan hidupnya.

\section{Persentase Parasitisasi Hymenoptera Parasitoid}

Hasil menunjukkan bahwa persentase parasitisasi Hymenoptera parasitoid terhadap hama pemakan daun kelapa sawit bervariasi (Tabel 2).

Tabel 2

Persen parasitisasi Hymenoptera parasitoid terhadap hama pemakan daun kelapa sawit di kebun kelapa sawit PTPN VIII Cindali, Bogor

\begin{tabular}{clc}
\hline Parasitoid & \multicolumn{1}{c}{ Inang } & $\begin{array}{c}\% \\
\text { parasitisasi }\end{array}$ \\
& & \\
\hline Spinaria spinator & Setora nitens & 85.71 \\
& Amatissa $\mathrm{sp}$. & 75 \\
Charops bicolor & Setora nitens & 28.57 \\
Telenomus podisi & Birthosea bisura & 76.92 \\
& Mahasena corbetti & 7.84 \\
Aphanogmus $\mathrm{sp}$. & Metisa plana & 6.70 \\
& Pseudococcus $\mathrm{sp}$. & 3.83 \\
\hline
\end{tabular}

Pengendalian hama pemakan daun kelapa sawit dengan menggunakan parasitoid menunjukkan potensial yang tinggi. Kompleksitas parasitoid yang didapat menunjukkan bahwa terdapat parasitoid yang memarasit berbagai stadia hama pemakan daun kelapa sawit, kecuali dewasa.

Persen parasitisasi tertinggi ditunjukkan oleh S. spinator yang memarasit dari larva Setora nitens. Hal ini sesuai dengan penelitian dari Hanysyam et al. (2013), bahwa S. spinator diketahui telah menjadi parasitoid utama pada ulat api di kebun kelapa sawit. Selain S. spinator persentase parasitisasi parasitoid lain juga terhitung tinggi. Hal ini dapat dikarenakan perbedaan pemanfaatan dari stadia inang, sehingga masingmasing parasitoid memiliki niche yang berbeda. Perbedaan habitat atau niche dan cara hidup dapat memungkinkan suatu kelompok organisme mengeksploitasi sumber makanan yang sama (Wylie \& Speight, 21012). Dapat dilihat parasitoid yang memiliki persen parasitisasi tinggi memiliki preferensi stadia inang ataupun inang yang berbeda. $S$. spinator biasanya menyerang pada stadia larva, $C$. bicolor menyerang stadia larva tetapi menyebabkan kematian pada saat pupa, dan T. podisi menyerang pada stadia telur. Selain perbedaan stadia, perbedaan inang yang di parasit juga menyebabkan tingginya persen parasitisasi dari parasitoid tersebut. S. spinator menyerang Setora nitens dan Amatissa sp., C. bicolor menyerang Setora nitens, dan T. podisi menyerang Birthosea bisura. Persen parasitisasi paling sedikit ditunjukan oleh Acerophagus sp. yang memarasit Pseudococcus sp. Hal ini disebabkan Pseudococcus sp. bukan merupakan hama utama pada tanaman kelapa sawit, sehingga kelimpahan hama tersebut pada tanaman kelapa sawit sedikit. Hal ini yang menyebabkan persen parasitisasi Acerophagus sp. rendah pada Pseudococcus sp. Selain itu, Acerophagus sp. Biasanya menyerang hama pembuat puru atau scale insect (Jahnke et al. 2007; Nalini \& Manickavasagam 2011), sehingga keberadaan parasitoid ini tidak ditemukan pada hama pemakan daun kelapa sawit.

\section{KESIMPULAN}

Terdapat 6 jenis hama pemakan daun kelapa sawit dan 5 jenis Hymeoptera parasitoid yang memarasitinya di kebun kelapa sawit PTPN VIII Cindali, Bogor. Parasitoid dengan persentase parasitisaasi paling tinggi adalah Spinaria spinator, sedangkan parasitoid dengan persentase parasitisasi paling rendah adalah Acerophagus sp. Pemanfaatan parasitoid untuk mengendalikan populasi hama pemakan daun kelapa sawit di lapang sangat potensial dilakukan berdasarkan nilai persentase parasitisasi.

\section{SANWACANA}

Ucapan terimakasih penulis berikan kepada Lembaga Penelitian UAD yang telah memberikan bantuan dana penelitian. Selain itu, ucapan terimakasih juga peneliti berikan kepada Dinas Pertanian Yogyakarta yang telah memberikan izin untuk menggunakan kebun Plasma Nutfah sebagai tempat penelitian.

\section{DAFTAR PUSTAKA}

Blumberg D. 2008. Date palm arthropod pests and their management in Israel. Phytoparasitica. 36(5): 411-448.

Cheong YL, Sajab AS, Hafidzi NM, Omar D, Abod F. 2010. Outbreak of bagworm and 
their natural enemies on an oil palm, Elaeis guineensis, plantation at Hutan $\mathrm{Me}$ lintang, Perak, Malaysia. J Entomol. 7: 141-151.

Cock MJ, Gallego CE \& Godfray HCJ. 2008. Penthocrates Meyrick (Lepidoptera: Limacodidae), a genus of new outbreak pests of coconut in the Philippines. Tro-pical Pest Management. 32(3): 201-206.

Costamagna AC, Menalled FD \& Landis DA. 2004. Host density influences parasitism of the armyworm Pseudaletia unipuncta in agricultural landscapes. Basic and Applied Ecology. 5: 347-355.

Dhileepan K. 1996. Parasitoids and predators of insects associated with oil palm (Elaeis guineensis Jacq.) in India. Elaeis. 8(2): 6474.

Gibson GAP, Huber JT \& Woolley JB. 1997. Annotated Keys to the Genera of Neartic Chalcidoidea (Hymenoptera). Ottawa, Canada (CA): NRC Research Press.

Goulet H \& Huber JT. 1993. Hymenoptera of the World: An Identification Guide to Families. Ottawa (UK): Centre for land and Biological Resources Research.

Grissell EE \& Schauff ME. 1990. A Handbook of the Families of Nearctic Chalcidoidea (Hymenoptera). Washington (US): The Entomological Society of Washington.

Halim M, Muhaimin AMD, Syarifah ZSA, Nor Atikah AR, Masri MMM, Yaakop S. 2017. Evaluation of infestation in parasitoids on Metisa plana Walker (Lepidoptera: Psychidae) in three oil palm plantations in peninsular Malaysia. Serangga. 22(2): 135-149.

Hanysyam MNM, Fauziah I, Khairiyah MHS, Fairuz K, et al. 2013. Assesment on the diversity of parasitoids of bagworms (Lepidoptera: Psychidae) in FELDA Gunung Besout 6, Sungkai, Perak. SHUSER. 2013: 130-135.

Hertslet IR \& Duckett JE. 1971. Thosea bisura. A new major pest of oil palms. Planter. 47: 398-404.

Hindarto A. 2015. Keanekaragaman serangga pada perkebunan kelapa sawit pada umur tanaman yang berbeda di unit Kebun
Rambutan PTPN III [Tesis]. Bogor (ID): Institut Pertanian Bogor.

Idris AB. 2001. Preliminary study on differential abundance and diversity of Ichneumonids and Braconids in star fruit orchard and oil palm plantations. PJBS. 4(8): 958-959.

Jahnke SM, Redaelli LZ, Diefenbach LMG \& Dal Soglio FK. 2007. Structure and composition of the assemblage of parasitoids associated to Phyllocnistis citrella pupae Stainton (Lepidoptera: Gracillariidae) in citrus orchards in Southern Brazil. Bio Control. 36(5): 746-751.

Kaeslin M, Wehrle I, Grossniklaus-Burgin C, Wyler T, Guggisberg U, Schittny JC \& Lanzrein B. 2004. Stage-dependent strategies of host invasion in the egg-larval parasitoid Chelonus inanitus. Journal of Insect Physiology. 51: 287-296.

Kamarudin NH, Walker AK, Wahid MB, LaSalle J \& Polaszek A. 1996. Hymenopterous parasitoids associated with the bagworms Metisa plana and Mahasena corbetti (Lepidoptera: Psychidae) on oil palms in Peninsular Malaysia. Bull of Entomol Res 86: 423-439.

Kiswanto, Purwanto HJ \& Wijayanto B. 2008. Teknologi Budidaya Kelapa Sawit. Badan Penelitian dan Pengembangan Pertanian. Lampung (ID): BPTP.

Mariau D. 1999. Limacodidae (Lepidoptera) on oil palm and coconut, Harmful species and natural enemies. Retour Au Menu. (1999): 158-160.

Marino PC, Landis DA \& Hawkins BA. 2005. Conserving parasitoid assemblages of North American pest Lepidoptera: Does biological control by native parasitoids depend on landscape complexity?. Biological Control. 37: 173-185.

Nalini T \& Manickavasagam S. 2011. Record of Encyrtidae (Hymenoptera: Chalcidoidea) parasitoids on mealybugs (Hemiptera: Pseudococcidae) from Tamil Nadu, India. J Species Lists and Distribution. 7(4): 510515.

Pratissoli D, de Freitas Bueno A, de Freitas Bueno RCO, Zanuncio JC \& Polancyzk RA. 2009. Revista Brasileira de Entomologia. 53(1): 151-153. 
Rao VP, Ghani MA, Sankaran T \& Mathur KC. 1971. A review of biological control of insects and other pests in South East Asia and Pacific Region. CAB Tech Comm. 6: 164.
Wylie FR \& Speight MR. 2012. Insect Pest in Tropical Forestry. $2^{\text {nd }}$ edition. Cambridge (US): CABI. 